\title{
Tumor Necrosis Factor System Activity Is Associated With Insulin Resistance and Dyslipidemia in Myotonic Dystrophy
}

\author{
José Manuel Fernández-Real, Ana Molina, Montserrat Broch, Wifredo Ricart, Cristina Gutiérrez, \\ Roser Casamitjana, Joan Vendrell, Joan Soler, and José Manuel Gómez-Sáez
}

\begin{abstract}
Myotonic dystrophy (MyD) is a multisystem autosomal dominant disorder associated with progressive muscle wasting and weakness. The striking metabolic abnormality in MyD is insulin resistance. The mechanism by which target tissues are insensitive to insulin action remains uncertain. In a recent study, plasma soluble tumor necrosis factor receptor (sTNFR)2 levels were found to be associated with muscle tissue mass and insulin resistance. Given these associations, we speculated that disorders of the muscle cell membrane could lead simultaneously to insulin insensitivity and sTNFR2 leakage in MyD. To test this hypothesis, we measured the levels of circulating sTNFR1 and sTNFR2 and insulin resistance in MyD patients. We studied 22 MyD patients and 24 age-, BMI-, and fat mass-matched control subjects. Both MyD men and women showed higher plasma insulin levels in the presence of comparable glucose concentrations than did control subjects. STNFR2, but not STNFR1, levels were $\sim 1.5$-fold higher in MyD patients. In parallel with these findings, the fasting insulin resistance index (FIRI) was also higher in MyD patients. In fact, in the whole population, fasting insulin and FIRI strongly correlated with sTNFR2 in both men $(r=0.77$ and $r=0.81, P<0.0001$, respectively $)$ and women $(r=0.67$ and $r=0.64, P=0.001$, respectively). sTNFR2 levels were also associated with the insulin sensitivity index $\left(S_{\mathrm{I}}\right)$, calculated from an oral glucose tolerance test (OGTT) according to the method by Cederholm and Wibell $(r=-0.43, P=0.006)$. We constructed a multiple linear regression to predict FIRI, with BMI, waist-to-hip ratio, and STNFR2 as independent variables. In this model, both BMI $(P=0.0014)$ and
\end{abstract}

From the Unitat de Diabetes, Endocrinologia, i Nutrició (J.M.F.-R., W.R.) University Hospital of Girona "Dr. Josep Trueta," Girona; the Departament de Endocrinologia (A.M., J.S., J.M.G.-S.), University Hospital of Bellvitge, Barcelona; the Unitat de Endocrinologia (M.B., C.G., J.V.), Hospital of Tarragona Joan XXIII, Departament de Medicina i Cirurgia, Universitat Rovira i Virgili, Tarragona; and the Hormonal Laboratory (R.C.), University Hospital Clínic, Barcelona, Spain.

Address correspondence and reprint requests to J.M. Fernández-Real, MD, PhD, Department of Endocrinology, Hospital de Girona, Carretera de França s/n, 17007 Girona, Spain. E-mail: hosptrueta@comg.es.

Received for publication 1 September 1998 and accepted in revised form 19 January 1999

CK, creatine kinase; CV, coefficient of variation; EASIA, enzyme-amplified sensitivity immunoassay; FIRI, fasting insulin resistance index FSIVGTT, frequently sampled intravenous glucose tolerance test; IRMA, immunoradiometric assay; MBG, mean blood glucose; MCR, metabolic clearance rate; MSI, mean serum insulin; MyD, myotonic dystrophy; OGL, oral glucose load; OGTT, oral glucose tolerance test; PK, protein kinase; $S_{\mathrm{I}}$, insulin sensitivity index; sTNFR, soluble tumor necrosis factor receptor TNF, tumor necrosis factor; TNFR, tumor necrosis factor receptor; WHR, waist-to-hip ratio.
STNFR2 $(P=0.0048)$ levels contributed independently to $46 \%$ of the variance of FIRI. In another model, in which FIRI was substituted for $S_{\text {I from the OGTT, both }}$ BMI $(P=0.0001)$ and sTNFR2 $(P=0.04)$ levels contributed independently to $48 \%$ of the variance of $S_{\mathrm{I}}$ from the OGTT. Plasma cholesterol and triglyceride concentrations were significantly increased in MyD patients. STNFR1 and sTNFR2 levels were found to be strongly associated with plasma cholesterol, LDL cholesterol, and triglycerides. sTNFR1 and sTNFR2 also correlated with serum creatine kinase activity in MyD patients $(r=0.57, P=0.006 ; r=0.75, P<0.0001$, respectively). In conclusion, here we describe, for the first time to our knowledge, a relationship between insulin action and plasma sTNFR2 concentration in MyD patients. We have also found increased concentrations of plasma triglycerides and cholesterol levels in parallel with sTNFR1 and STNFR2 concentrations in MyD patients. We speculate that the latter associations are dependent on, and secondary to, increased tumor necrosis factor (TNF)- $\alpha$ action. Whether TNF action is implicated in the pathogenesis of MyD or is a simple marker of disease activity awaits further studies. Diabetes 48:1108-1112, 1999

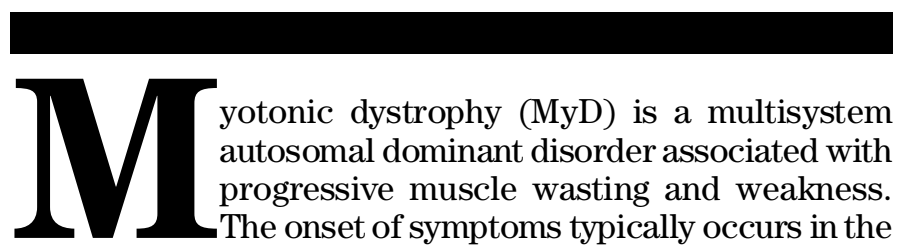
2nd and 3rd decades of life. MyD is the most common adult form of muscular dystrophy, with an estimated prevalence of 1 in 8,000 (1). The MyD gene has been identified as an expansion mutation of a trinucleotide repeat at chromosome region $19 \mathrm{q} 13.3(2)$. The gene product is a protein kinase (PK) of metabolic importance to muscle.

The striking metabolic abnormality in $\mathrm{MyD}$ is insulin resistance. Marked hyperinsulinemia after oral glucose, intravenous glucose, tolbutamide, glucagon, or arginine tolerance tests is observed in MyD patients $(3,4)$. The mechanism by which target tissues are insensitive to insulin action remains uncertain, although a receptor or postreceptor defect has been suggested $(3,4)$.

In recent years, it has been demonstrated that tumor necrosis factor (TNF)- $\alpha$ has important effects on whole-body lipid and glucose metabolism $(5,6)$. TNF- $\alpha$ is a candidate mediator of insulin resistance because it is overexpressed in the adipose and muscle tissues of rodents and humans and 
blocks the action of insulin in cultured cells and whole animals (7-9). The induction of insulin resistance is mediated through TNF- $\alpha$ 's ability to produce serine phosphorylation of insulin receptor substrate-1, decreasing the tyrosine kinase activity of the insulin receptor (10).

TNF signals through at least two known cell surface receptors (TNFRs), TNFR1 (p55) and TNFR2 (p75), that are present in virtually all cells of higher mammals (11-13). It appears that TNFR1 can signal for virtually all known activities of TNF, including apoptosis, differentiation, and proliferation. TNFR2 seems to signal metabolic actions (13). Both receptors for TNF exist also in soluble forms $(14,15)$, apparently derived by proteolytic cleavage from the cell surface forms (16). These soluble TNFRs (sTNFRs) can compete with the cell surface receptors and thus block their activity. However, sTNFRs affect TNF function also by stabilizing TNF activity, most likely by preventing dissociation of the homotrimeric TNF molecules to inactive monomers (16). It has been suggested that sTNFR1 and sTNFR2 represent markers of previous $\mathrm{TNF}-\alpha$ activity by forming a "slow release reservoir" and impeding spontaneous denaturation of the cytokine, remaining elevated for several days after TNF- $\alpha$ administration (16).

In a recent study, obese women expressed approximately twofold more TNFR2 mRNA in fat tissue and approximately sixfold more sTNFR2 in circulation relative to lean control subjects (17). Adipose tissue TNFR2 expression strongly correlated with BMI and the level of insulinemia. We have recently found that plasma sTNFR2 levels were inversely associated with insulin sensitivity in healthy subjects (18). Furthermore, sTNFR2 levels correlated positively with parameters of the muscle compartment, such as fat-free mass, midarm muscle circumference, and mid-arm muscle area (18). In contrast, no correlation was observed between any metabolic variable and adipose tissue TNFR1 expression (17) or plasma sTNFR1 levels (18).

Muscle fibers displayed enhanced expression of TNF- $\alpha$, and upregulation of cytokines was strongest at sites of cellular infiltration, typical for the respective myositis subtype in two recent studies dealing with inflammatory myopathies $(19,20)$. Unfortunately, MyD patients were not included in these reports. We are unaware of any study investigating TNF expression or TNF action in MyD. Given the associations between sTNFR2 levels and the muscle compartment, we speculated that disorders of the muscle cell membrane could lead simultaneously to insulin insensitivity and sTNFR2 leakage. To test this hypothesis, we measured the levels of circulating sTNFR1 and sTNFR2 and insulin resistance in $\mathrm{MyD}$ patients.

\section{RESEARCH DESIGN AND METHODS}

Subjects. We studied $22 \mathrm{MyD}$ patients and 24 control subjects who were similar in age, BMI, and fat mass (Table 1). Characteristics of the subjects are summarized in Table 1. MyD diagnosis was based on clinical measures and on evidence of CTG repeats in the $3^{\prime}$-untranslated region of the gene involved in $\mathrm{MyD}$ pathogenesis. Inclusion criteria for patients and subjects included 1) BMI (weight in kilograms divided by the square of height in meters) $<40 \mathrm{~kg} / \mathrm{m}^{2}$; 2) absence of any systemic disease other than MyD; and 3) absence of any infections in the previous month. None of the subjects were taking any medication known to interfere with glucose or lipid metabolism or had any evidence of metabolic disease other than obesity. All reported that their body weight had been stable for at least 3 months before the study. Metabolic and hormonal data on some of the subjects were reported previously (18). The protocol was approved by the hospital ethics committee, and informed consent was obtained from each subject.

Anthropometric measurement. All subjects were evaluated, in addition to BMI, through the waist-to-hip ratio (WHR), as previously described (18). The percentage of body fat and fat-free mass were measured by bioelectric impedance analysis (Holtain BC Analyser, London, U.K.).

Study protocol. An oral glucose tolerance test (OGTT) was performed according to the recommendations of the National Diabetes Data Group (21). After a 12-h overnight fast, glucose was ingested in a dose of $75 \mathrm{~g}$, and blood samples were collected through a venous catheter from an antecubital vein at $0,30,60,90$, and $120 \mathrm{~min}$ for measurement of serum glucose. The glucose (mean blood glucose [MBG]) and insulin (mean serum insulin [MSI]) total areas under the curve during the OGTT were determined by the trapezoidal method. The degree of peripheral sensitivity to insulin was estimated during the OGTT according to the method validated by Cederholm and Wibell (22). In this method, as in the minimal model developed by Bergman et al. (23), the glucose-insulin homeostatic system is considered to be divided into two parts, pancreatic responsiveness and peripheral cell responsiveness, permitting analysis of each part by input and output observations without disrupting the glucose-insulin feedback relationship (22). The glucose uptake rate in peripheral target tissues $(M)$ is expressed as milligrams per minute and is calculated according to the following formula: $M=\mathrm{OGL} / 120+\left[\left(\mathrm{G}_{0}-\mathrm{G}_{120}\right) \times 0.19 \times \mathrm{BW}\right] / 120$, where OGL is the oral glucose load $(75,000 \mathrm{mg})$, which was used as a constant factor; $\mathrm{G}_{0}-\mathrm{G}_{120}$ is the amount of glucose at the fasting level minus the amount at 120 min, representing the part of the OGL left in the glucose space after $2 \mathrm{~h}$; and BW is the body weight in kilograms. The factor 120 converted $2 \mathrm{~h}$ into minutes. When the glucose uptake rate is evaluated during clamp tests, it is usually expressed as the metabolic clearance rate (MCR) to avoid the influence of different blood glucose levels on the uptake rate. For the purpose of assessing the insulin sensitivity index

TABLE 1

Anthropometric and biochemical variables

\begin{tabular}{|c|c|c|c|c|c|c|}
\hline & MyD men & Control men & $P$ value & MyD women & Control women & $P$ value \\
\hline$n$ & 8 & 11 & - & 14 & 13 & - \\
\hline Age (years) & $38.5 \pm 9.6$ & $39.1 \pm 6.7$ & NS & $38.7 \pm 5.9$ & $42.3 \pm 10$ & NS \\
\hline $\mathrm{BMI}\left(\mathrm{kg} / \mathrm{m}^{2}\right)$ & $26.8 \pm 2.2$ & $26.9 \pm 3.7$ & NS & $32.9 \pm 2.2$ & $32.5 \pm 2.7$ & NS \\
\hline WHR & $0.98 \pm 0.2$ & $0.94 \pm 0.3$ & NS & $0.89 \pm 0.3$ & $0.91 \pm 0.4$ & NS \\
\hline Fat mass (kg) & $23.1 \pm 9.6$ & $19.1 \pm 9.57$ & NS & $22.2 \pm 10$ & $26.9 \pm 12.4$ & NS \\
\hline Percent fat mass (\%) & $30.6 \pm 12.3$ & $21.9 \pm 9.5$ & NS & $28.6 \pm 10.2$ & $33.5 \pm 11.1$ & NS \\
\hline sTNFR1 $(\mathrm{ng} / \mathrm{ml})$ & $2.1 \pm 0.8$ & $1.61 \pm 0.14$ & NS & $1.81 \pm 0.7$ & $1.45 \pm 0.26$ & 0.08 \\
\hline sNTFR2 (ng/ml) & $4.51 \pm 1.6$ & $3.06 \pm 0.2$ & 0.04 & $3.91 \pm 1.17$ & $2.62 \pm 0.28$ & 0.001 \\
\hline Fasting glucose (mmol/l) & $5.27 \pm 0.49$ & $5.45 \pm 0.53$ & NS & $5.41 \pm 0.9$ & $5.38 \pm 1.3$ & NS \\
\hline Fasting insulin (mU/l) & $15.4 \pm 8$ & $8.7 \pm 3.1$ & 0.021 & $20.7 \pm 11$ & $9.9 \pm 5.4$ & 0.003 \\
\hline FIRI & $3.2 \pm 1.34$ & $1.94 \pm 0.86$ & 0.031 & $4.7 \pm 2.5$ & $2.16 \pm 1.3$ & 0.003 \\
\hline Cholesterol (mmol/l) & $5.91 \pm 0.8$ & $5.24 \pm 0.75$ & 0.08 & $5.6 \pm 0.8$ & $5.25 \pm 0.8$ & NS \\
\hline LDL cholesterol (mmol) & $4.6 \pm 0.6$ & $3.8 \pm 0.7$ & 0.05 & $4.3 \pm 0.5$ & $3.6 \pm 0.8$ & 0.019 \\
\hline Triglycerides (mmol/l) & $2.03 \pm 0.4$ & $1.19 \pm 0.4$ & 0.001 & $2.41 \pm 0.37$ & $1.33 \pm 0.8$ & 0.001 \\
\hline
\end{tabular}

Data are means $\pm \mathrm{SD}$ or $n$. 


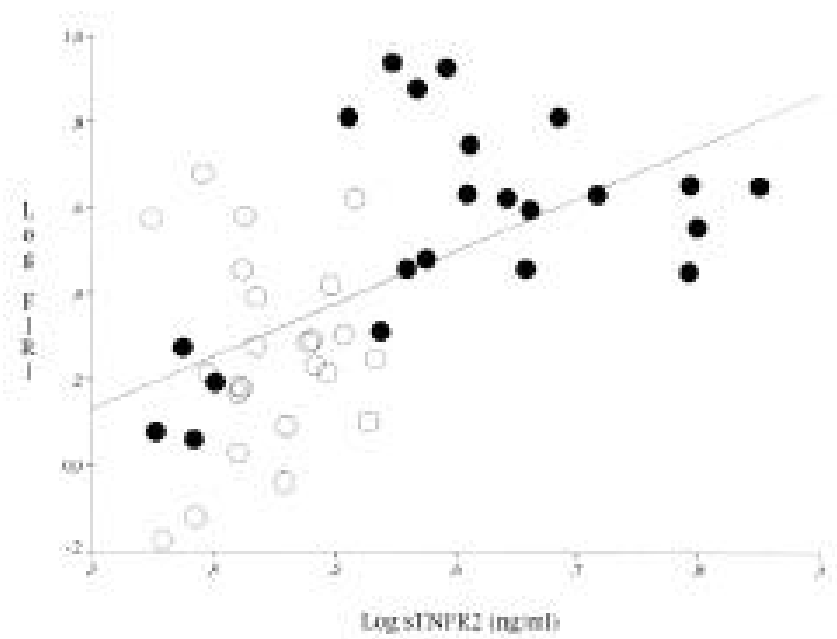

FIG. 1. Linear correlation between circulating sTNFR2 levels and FIRI $(r=0.57, P<0.0001)$, MyD patients.

$\left(S_{\mathrm{I}}\right)$, the MCR during the OGTT was estimated by correcting the $M$ value with MBG during the 2 -h test $\left(\mathrm{MCR}\left[\mathrm{mg} \cdot \mathrm{l}^{-1} \cdot \mathrm{mmol} \cdot \mathrm{l}^{-1} \cdot \mathrm{min}^{-1}\right]=M / \mathrm{MBG}\right) . S_{\mathrm{I}}$ was then calculated as MCR/log MSI during the OGTT. Thus, the $S_{\mathrm{I}}$ value, as defined here, is an approximate numerical index of the curve relating the MCR to the log of insulin during clamp tests in a test where a constant OGL is given. In our hands, $S_{\mathrm{I}}$ calculated from the OGTT correlated with $S_{\mathrm{I}}$ calculated from the frequently sampled intravenous glucose tolerance test (FSIVGTT) with minimal model analysis $(r=0.72, P$ $<0.0001, n=46)$ (J.M.F.-R., W.R., R.C., unpublished observations).

Insulin resistance was also calculated through the fasting insulin resistance index $($ FIRI). FIRI $=$ fasting glucose $(\mathrm{mmol} / \mathrm{l}) \times$ fasting insulin $(\mathrm{mU} / \mathrm{l}) / 25$. In our experience, FIRI fairly correlates with the $S_{\mathrm{I}}$ calculated from FSIVGTT with minimal model analysis ( $r=0.79, P<0.0001, n=46)$ (J.M.F.-R., W.R., R.C., unpublished observations). Analytical methods. The serum glucose level during the OGTT was measured in duplicate by the glucose oxidase method with a glucose analyzer 2 (Beckman, Brea, CA). The coefficient of variation (CV) was $1.9 \%$. The serum insulin level was measured in duplicate by monoclonal immunoradiometric assay (IRMA) (Medgenix Diagnostics, Fleunes, Belgium). The lowest limit of detection was $4.0 \mathrm{mU} / \mathrm{l}$. The intra- and interassay CVs were 5.2 and $6.9 \%$, respectively.

The Medgenix sTNF-R1 and sTNF-R2 solid-phase enzyme-amplified sensitivity immunoassays (EASIAs) (BioSource Europe, Fleunes, Belgium) were performed on microtiter plate. The minimum detectable concentration was estimated to be $0.1 \mathrm{ng} / \mathrm{ml}$ and was defined as the sTNFR1 or sTNFR2 concentration corresponding to the average optical density of 20 replicates of the zero standard +2 SDs. The intra- and interassay CVs were $<7$ and $<9 \%$. sTNFR1 EASIA does not cross-react with STNF-R2. TNF- $\alpha$ does not interfere with the assay.

Plasma TNF- $\alpha$ was measured using IRMA (Medgenix Diagnostics). Serum creatine kinase (CK) activity was measured by standard routine assays through the velocity of ATP synthesis when the enzyme is in contact with phosphocreatine and $\mathrm{ADP}$.

Total serum cholesterol was measured through the reaction of cholesterol esterase/cholesterol oxidase/peroxidase (24). VLDL cholesterol was measured after ultracentrifugation at $45,000 \mathrm{~g}$. HDL cholesterol was quantified after precipitation with polyethylene glycol at room temperature (25). Total serum triglycerides were measured through the reaction of glycerol-phosphate-oxidase and peroxidase (26). VLDL triglycerides were measured after ultracentrifugation at $45,000 \mathrm{~g}$. LDL cholesterol was calculated as total cholesterol (VLDL cholesterol + HDL cholesterol)

Statistical analyses. Descriptive results of continuous variables are expressed as means \pm SD. Non-Gaussian-distributed variables were $\log _{10}$ transformed to achieve normality. This applied to fasting levels of insulin, FIRI, $S_{\mathrm{I}}$ from the OGTT, sTNFR1, and sTNFR2. Relationships between variables were sought by Pearson's correlation coefficient and stepwise multivariate linear regression analysis with forward selection. The regression coefficient generated by this analysis indicates the slope of the association between the dependent variable and the specified independent variable, after adjusting for other independent variables in the model. The SE represents the variability in this association, and the significance is reflected by the $P$ value. Comparison of variables across lean and obese men and women was performed by one-way analysis of variance using Fisher's test for multiple comparisons. Levels of statistical significance were set at $P<0.05$.

All these analyses were performed with the BMDP statistical package (BMD Statistical Software, Cork, Ireland).

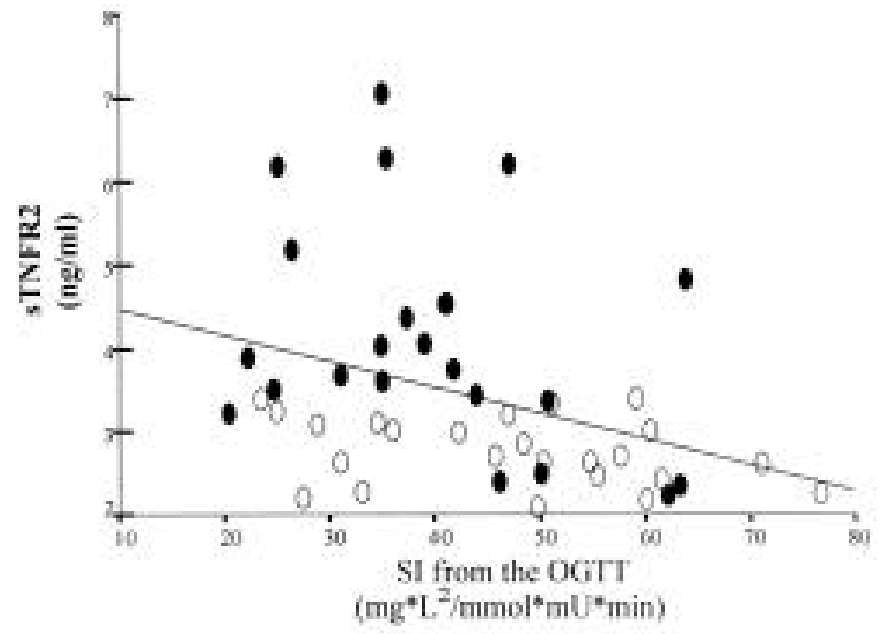

FIG. 2. Linear correlation between circulating sTNFR2 levels and $S_{\mathrm{I}}$ obtained from the OGTT in all subjects $(r=-0.43, P=0.006, n=46)$. , MyD patients.

\section{RESULTS}

Anthropometric and biochemical characteristics of the subjects are shown in Table 1. Time since diagnosis of MyD had no effect on any of the parameters measured. In our study sample, no significant correlations between either sTNFR1 or sTNFR2 and BMI were found in either control subjects $(r=0.08$ and $r$ $=0.29$ [NS], respectively) or MyD patients $(r=0.24[\mathrm{NS}]$ and $r$ $=0.36[P=0.09]$, respectively). This is in contrast to previous observations in subjects with significantly higher BMI $(17,18)$ or with a wider range of BMI than in this study sample (18). By excluding subjects with higher BMI and sTNFR2 levels, we are weakening the relationship between BMI and sTNFR2. In MyD patients, the lack of association was due to disproportionately increased sTNFR2 levels in patients with low BMI.

Both men and women MyD patients showed higher plasma insulin levels than control subjects in the presence of comparable glucose concentrations. sTNFR2, but not sTNFR1, levels were 1.5-fold higher in MyD patients (Table 1). In parallel with these findings, FIRI was also higher in MyD patients. In fact, in the whole population, fasting insulin and FIRI strongly correlated with sTNFR2 in both men $(r=0.77$ and $r=0.81, P<0.0001$, respectively) and women $(r=0.67$ and $r=0.64, P=0.001$, respectively) $(r=0.57, P<0.0001$, in all subjects) (Fig. 1). sTNFR2 levels were also associated with the $S_{\mathrm{I}}$ calculated from the OGTT ( $\left.r=-0.43, P=0.006\right)$ (Fig. 2). We constructed a multiple linear regression model to predict FIRI, with BMI, WHR, and sTNFR2 as independent variables. In this model, both BMI $(P=0.0014)$ and sTNFR2 $(P=0.0048)$ levels contributed independently to $46 \%$ of the variance of FIRI. In another model, in which FIRI was substituted for $S_{\text {I }}$ from the OGTT, both BMI $(P=0.0001)$ and sTNFR2 $(P=0.04)$ levels contributed independently to $48 \%$ of the variance of $S_{\mathrm{I}}$ from the OGTT.

Plasma TNF- $\alpha$ levels were below the linear range of the assay in $55 \%$ of the patients. This finding precludes a correct interpretation of circulating $\mathrm{TNF}-\alpha$.

Plasma LDL cholesterol and triglyceride concentrations were significantly increased in MyD patients (Table 1). However, it is important to note that LDL measurements were inferred by subtraction, and this approach may not be accurate given the elevated triglycerides. sTNFR1 and sTNFR2 


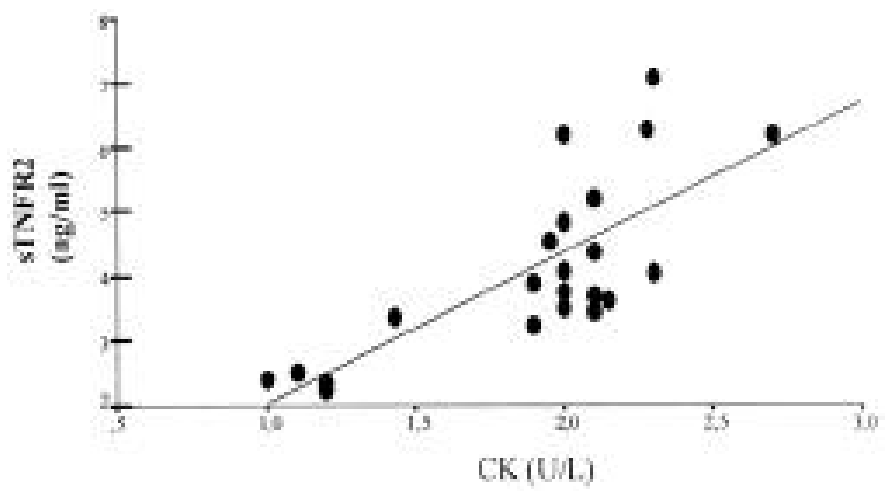

FIG. 3. Linear correlations between circulating sTNFR2 levels and serum CK in MyD patients $(r=0.75, P<0.0001, n=22)$.

levels were found to be strongly associated with plasma cholesterol, LDL cholesterol, and triglycerides (Table 2). Plasma sTNFR1 and sTNFR2 levels also correlated with serum CK activity in MyD patients $(r=0.57[P=0.006]$ and $r=0.75[P<0.0001]$ for sTNFR1 and sTNFR2, respectively) (Fig. 3).

\section{DISCUSSION}

The correlation between fasting insulin, FIRI, the $S_{\mathrm{I}}$ obtained from the OGTT, and sTNFR2 suggests that both glucose and sTNFR2 might be regulated by the same related signal. In fact, increased expression of TNF- $\alpha$ strongly correlates with the level of hyperinsulinemia (8) and the glucose disposal rate during euglycemic clamp technique (9). Because TNF- $\alpha$ is a strong inducer of TNFR2 expression in adipocytes (17) and other cell types (27), the negative correlation between insulin sensitivity and sTNFR2 might be attributed to increased TNF- $\alpha$ action in situations of insulin resistance. Marked hyperinsulinemia after OGTT is well known in MyD patients $(3,4,28)$, and here we describe, for the first time to our knowledge, a relationship between insulin action and plasma sTNFR2 concentration in MyD patients.

sTNFRs are present constitutively in serum at concentrations that increase significantly in both inflammatory and noninflammatory disease states (29). TNFRs may in some situations inhibit the effects of TNF, in others, serve as carriers for TNF, and in some cases they may even augment the effects of TNF by prolonging its function (16). The study of the mechanisms that control TNFR function will provide new insights in the pathogenesis of insulin action in general and in the etiology of insulin resistance in $\mathrm{MyD}$.

Glucose transport and oxidation are decreased in adipose tissue-the main metabolic target of $\mathrm{TNF}-\alpha$-in MyD patients (30). A decreased phosphorylation of muscle sar- colemma due to deficient PK activity in muscle obtained from MyD patients has been described (31). Although this deficient PK activity is probably of genetic origin (2), it will be important to study whether these alterations in PK are amplified by increased TNF- $\alpha$ action (comparable to the reduction in tyrosine kinase activity of the insulin receptor induced by TNF- $\alpha$ [10]). The association between sTNFRs and CK is in concordance with the action of recombinant human TNF- $\alpha$ in vivo, which yielded higher serum CK values after its intravenous administration in melanoma patients (32).

In the last years, it has been demonstrated that $\mathrm{TNF}-\alpha$ has important effects on whole-body lipid metabolism (33). TNF actions are thought to cause hypertriglyceridemia due to decreased lipolysis and increased VLDL secretion (33). Hypertriglyceridemia is well described in patients with the acquired immunodeficiency syndrome (34) or cystic fibrosis (35), two states of inferred high TNF- $\alpha$ action. Here we describe increased concentrations of plasma triglycerides and cholesterol levels in parallel with sTNFR1 and sTNFR2 concentrations in MyD patients. Interestingly, proinsulininsulin hypersecretion has already been found to correlate with the levels of cholesterol and triglyceride in $\mathrm{MyD}$ (36). We speculate that this latter association is dependent on, and secondary to, increased TNF- $\alpha$ action. TNF- $\alpha$ has been found to produce a $25 \%$ increase in serum cholesterol levels and a 2.3-fold increase in hepatic hydro-3-methyl-glutaryl CoA reductase activity in $\mathrm{C} 57 \mathrm{Bl} / 6$ mice (37). TNF- $\alpha$ is also capable of inducing sterol regulatory element binding protein-1 maturation, a key transcription factor in cholesterol biosynthesis, in a time- and dose-dependent manner (38). In conditions in which acute TNF secretion is not induced, increased cholesterol levels might be the first event, with TNF hypersecretion being secondary to lipid derangement. In this sense, the accumulation of cholesteryl esters in macrophages exposed to LDL immune complexes is associated with increased synthesis and release of TNF- $\alpha$ (39). Increased TNF secretion has also been observed in hypercholesterolemic rabbits (40) and in LDL receptor knockout mice, in which plasma TNF- $\alpha$ levels are elevated in parallel with LDL cholesterol (41). Furthermore, atherogenic diets enhance endotoxin-stimulated TNF- $\alpha$ gene expression in rabbit aortae (42). The implications of our findings are potentially important in the sense that sTNFR1 and sTNFR2 could constitute markers of atherosclerosis.

In summary, plasma sTNFR1 and sTNFR2 levels are associated with several metabolic abnormalities in MyD patients. Whether TNF action is implicated in the pathogenesis of $\mathrm{MyD}$ or is a simple marker of disease activity awaits further studies.

\section{ACKNOWLEDGMENTS}

This work was partially supported by Comision Asesora de Investigacion Cientifica y Tecnica SAF Grant 98-0130.

TABLE 2

Correlation between sTNFR1, sTNFR2, and lipid parameters

\begin{tabular}{lccc}
\hline & Cholesterol & LDL cholesterol & Triglycerides \\
\hline sTNFR1 & $0.58(P<0.001)$ & $0.62(P<0.0001)$ & $0.41(P<0.005)$ \\
sTNFR2 & $0.60(P<0.0001)$ & $0.65(P<0.0001)$ & $0.59(P<0.0001)$ \\
\hline
\end{tabular}




\section{REFERENCES}

1. Harper PS: Myotonic disorders. In Myology. Engel AG, Banker BQ, Eds. New York, McGraw-Hill, 1986, p. 1267-1311

2. Aslanidis C, Jansen G, Ameniya C, Shutler G, Mahadevan M, Tsilfidis C, Chen C, Alleman J, Wormskamp NGM, Vooijs M, Buxton J, Johnson K, Smeels HJM, Lennon GG, Carrano AV, Korneluk RG, Wieringa B, De Jong PJ: Cloning of the essential myotonic dystrophy region and mapping of the putative defect. Nature 353:548-551, 1992

3. Tevaarwerk GJM, Strickland KP, Lin CH, Hudson AJ: Studies on insulin resistance and insulin receptor binding in myotonia dystrophica. J Clin Endocrinol Metab 49:216-222, 1979

4. Moxley RT III, Griggs RC, Goldblat D: Muscle insulin resistance in myotonic dystrophy: effect of supraphysiologic insulinization. Neurology 30:1977-1083, 1980

5 . Beutler B, Cerami A: The biology of cachectin/TNF- $\alpha$ primary mediator of the host response. Annu Rev Immunol 7:625-655, 1989

6. Grunfeld C, Feingold KR: The metabolic effects of tumor necrosis factor and other cytokines. Biotherapy 3:143-158, 1991

7. Kern PA, Saghizadeh M, Ong JM, Bosch RJ, Deem R, Simsolo RB: The expression of tumor necrosis factor in human adipose tissue: regulation by obesity, weight loss, and relationship to lipoprotein lipase. J Clin Invest 95:2111-2119, 1995

8. Hotamisligil GS, Arner P, Caro JF, Atkinson RL, Spiegelman BM: Increased adipose tissue expression of tumor necrosis factor- $\alpha$ in human obesity and insulin resistance. J Clin Invest 95:2409-2415, 1995

9. Saghizadeh M, Ong JM, Garvey WT, Henry RR, Kern PA: The expression of TNF- $\alpha$ by human muscle: relationship to insulin resistance. $J$ Clin Invest 97:1111-1116, 1996

10. Hotamisligil GS, Peraldi P, Budavari A, Ellis R, White MF, Spiegelman BM: IRS 1 -mediated inhibition of insulin receptor tyrosine kinase activity in TNF- $\alpha-$ and obesity-induced insulin resistance. Science 271:665-668, 1996

11. Tartaglia LA, Goeddel DV: Two TNF receptors. Immunol Today 13:151-153, 1992

12. Smith CA, Farrah T, Goodwin RG: The TNF receptor superfamily of cellular and viral proteins: activation, costimulation, and death. Cell 76:959-962, 1994

13. Bazzoni F, Beutler B: The tumor necrosis factor ligand and receptor families. N Engl J Med 334:1717-1725, 1996

14. Seckinger P, Isaaz S, Dayer JM: Purification and biologic characterization of a specific tumor necrosis factor- $\alpha$ inhibitor. J Biol Chem 264:11966-11973, 1989

15. Nophar Y, Kemper O, Brakebusch C, Engelmann H, Zwang R, Aderka D, Holtmann H, Wallach D: Soluble forms of tumor necrosis factors (TNF-Rs): the cDNA for the type I TNF-R, cloned using amino acid sequence data of its soluble form, encodes both the cell surface and a soluble form of the receptor. EMBO J 9:3269-3278, 1990

16. Aderka D, Engelmann H, Maor Y, Brakebusch C, Wallach D: Stabilization of the bioactivity of tumor necrosis factor by its soluble receptors. J Exp Med 175:323-329, 1992

17. Hotamisligil GS, Arner P, Atkinson RL, Spiegelman BM: Differential regulation of the $\mathrm{p} 80$ tumor necrosis factor receptor in human obesity and insulin resistance. Diabetes 46:451-455, 1997

18. Fernández-Real JM, Broch M, Ricart W, Casamitjana R, Gutierrez C, Vendrell J, Richart C: Plasma sTNFR2 levels and insulin resistance. Diabetes 1998; 47:1757 1762

19. Lundberg I, Brengman JM, Engel AG: Analysis of cytokine expression in muscle in inflammatory myopathies, Duchenne dystrophy, and non-weak controls. J Neuroimmunol 63:9-16, 1995

20. Tews DS, Goebel HH: Cytokine expression profile in idiopathic inflammatory myopathies. J Neuropathol Exp Neurol 55:342-347, 1996

21. National Diabetes Data Group: Classification and diagnosis of diabetes mellitus and other categories of glucose intolerance. Diabetes 28:1039-1057, 1979

22. Cederholm J, Wibell L: Insulin release and peripheral sensitivity at the oral glu- cose tolerance test. Diabetes Res Clin Pract 10:167-175, 1990

23. Bergman RN, Prager R, Volund A, Olefsky JM: Equivalence of the insulin sensitivity index in man derived by the minimal model method and euglycaemic glucose clamp. J Clin Invest 79:790-800, 1987

24. Siedel J, Hagele EO, Ziegenhorn J, Wahlefeld AW: Reagent for the enzymatic determination of serum total cholesterol with improved lipolytic efficiency. Clin Chem 29:1075-1080, 1983

25. Kostner GM, Molinari E, Pichler P: Evaluation of a new HDL2/ HDL3 quantitation method based on precipitation with polyethylene glycol. Clin Chim Acta 148:139-147, 1985

26. Wahlefeld AW: Methoden der Enzymatischen Analyse. Bergmeyer HU, Ed. Vol II, 3rd ed. Weinheim, Germany, Verlag Chemie, 1974, p. 187-188

27. Winzen R, Wallach D, Kemper O, Resch K, Holtmann H: Selective upregulation of the 75-kDa tumor necrosis factor (TNF) receptor and its mRNA by TNF and IL-1. J Immunol 150:4346-4353, 1993

28. Gómez-Sáez JM, Fernández-Real JM, Fernández-Castañer M, Navarro Moreno MA, Martínez-Matos JA, Soler Ramón J: Study on growth hormone and insulin secretion in myotonic dystrophy. Clin Invest 72:508-511, 1994

29. Aderka D, Engelmann H, Hornik V, Skornick Y, Levo Y, Wallach D, Kustai G: Increased serum levels of soluble receptors for tumor necrosis factor in cancer patients. Cancer Res 51:5602-5607, 1991

30. Mably E, Strickland KP, Tevaarwerk GJ, Hudson AJ: Glucose transport and oxidation in adipose tissue of patients with myotonic dystrophy. J Neuro Sci 52:11-23, 1981

31. Roses AD, Appel SH: Muscle membrane protein kinase in myotonic muscular dystrophy. Nature 250:245-246, 1974

32. Hohenberger P, Haier J, Schlag PM: Rhabdomyolysis and renal function impairment after isolated limb perfusion: comparison between the effects of perfusion with rhTNF- $\alpha$ and a "triple-drug" regimen. Eur J Cancer 33:596-601, 1997

33. Grunfeld C, Feingold KR: Role of cytokines in inducing hyperlipidemia. Diabetes 41 (Suppl. 2): 97-101, 1992

34. Grunfeld C, Pang M, Doerrler W, Shigenaga JK, Jensen P, Feingold KR: Lipids, lipoproteins, triglyceride clearance, and cytokines in human immunodeficiency virus infection and the acquired immunodeficiency syndrome. J Clin Endocrinol Metab 74:1045-1052, 1992

35. Levy E, Gurbindo C, Lacaille F, Paradis K, Thibault L, Seidman E: Circulating tumor necrosis factor- $\alpha$ levels and lipid abnormalities in patients with cystic fibrosis. Pediatr Res 34:162-166, 1993

36. Poffenbarger PL, Bozefsky T, Soeldner JS: The direct relationship of proinsulininsulin hypersecretion to basal serum levels of cholesterol and triglyceride in myotonic dystrophy. J Lab Clin Med 87:384-396, 1976

37. Memon RA, Grunfeld C, Moser AH, Feingold KR: Tumor necrosis factor mediates the effect of endotoxin on cholesterol and triglyceride metabolism in mice. Endocrinology 132:2246-2253, 1993

38. Lawler JF Jr, Yin M, Diehl AM, Roberts E, Chatterjee S: Tumor necrosis factor- $\alpha$ stimulates the maturation of sterol regulatory element binding protein-1 in human hepatocytes through the action of neutral sphingomyelinase. J Biol Chem 273:5053-5059, 1998

39.Lopes-Virella M, Virella G: Cytokines, modified lipoproteins, and arteriosclerosis in diabetes. Diabetes 45 (Suppl. 3):S40-S44, 1996

40. Brito BE, Romano EL, Grunfeld C: Increase lipopolysaccharide-induced tumour necrosis factor levels and death in hypercholesterolaemic rabbits. Clin Exp Immunol 101:357-361, 1995

41. Henninger DD, Gerritsen ME, Granger DN: Low-density lipoprotein receptor knockout mice exhibit exaggerated microvascular responses to inflammatory stimuli. Circ Res 81:274-281, 1997

42. Fleet JC, Clinton SK, Salomon RN, Loppnow H, Libby P: Atherogenic diets enhance endotoxin-stimulated interleukin-1 and tumor necrosis factor gene expression in rabbit aortae. J Nutr 122:294-305, 1992 